\title{
BMJ Open Cross-sectional study examining the accuracy of self-reported smoking status as compared to urinary cotinine levels among workers at risk for chronic kidney disease of unknown origin in Guatemala
}

\author{
Jaime Butler-Dawson (10) , ${ }^{1,2}$ Joaquin Barnoya, ${ }^{3,4}$ Stephen Brindley, ${ }^{1}$ \\ Lyndsay Krisher, ${ }^{1,2}$ Wenyi Fan, ${ }^{2}$ Claudia Asensio, ${ }^{5}$ Lee S Newman ${ }^{1,2,6}$
}

To cite: Butler-Dawson J, Barnoya J, Brindley S, et al. Cross-sectional study examining the accuracy of self-reported smoking status as compared to urinary cotinine levels among workers at risk for chronic kidney disease of unknown origin in Guatemala. BMJ Open 2021;11:e050374. doi:10.1136/ bmjopen-2021-050374

- Prepublication history for this paper is available online. To view these files, please visit the journal online (http://dx.doi. org/10.1136/bmjopen-2021 050374).

Received 17 February 2021 Accepted 06 0ctober 2021

D) Check for updates

(c) Author(s) (or their employer(s)) 2021. Re-use permitted under CC BY-NC. No commercial re-use. See rights and permissions. Published by BMJ.

For numbered affiliations see end of article.

Correspondence to Dr Jaime Butler-Dawson; jaime.butler-dawson@ cuanschutz.edu

\section{ABSTRACT}

Objectives There is a lack of information on cotinine levels in rural populations in low-income and middleincome countries like Guatemala. Therefore, there is a need to explore smoking status and biomarkers of tobacco use in epidemiological research in rural, low-income populations, in particular those at-risk for chronic kidney disease of unknown origin (CKDu).

Design We evaluated self-reported smoking status against urinary cotinine levels, the gold standard biomarker of tobacco smoke exposure, among agricultural workers at four separate cross-sectional time points.

Setting Guatemala.

Participants 283 sugarcane workers.

Primary outcome measures Compared self-reported smoking status and urinary cotinine levels in two agricultural worker studies.

Results Self-reported smoking prevalence was $12 \%$ among workers. According to cotinine levels ( $\geq 50 \mathrm{ng} /$ $\mathrm{mL}$ ), the smoking prevalence was $34 \%$. Self-reported smoking status had $28 \%$ sensitivity and $96 \%$ specificity. Urinary cotinine levels show that smoking prevalence is underestimated in this worker population.

Conclusions According to our findings, smoking status should be objectively measured with biomarkers rather than self-reported in CKDu epidemiological research. Self-reported smoking status is likely an underestimate of the true smoking prevalence among agricultural workers. Research on the CKDu epidemic in Central America and other parts of the world might be underestimating tobacco exposure as a potential contributor to the development of CKDu.

\section{INTRODUCTION}

Smoking as a potential contributor to the development of chronic kidney disease of unknown origin $(\mathrm{CKDu})$ has not been fully explored and is often overlooked in CKDu research. The emerging CKDu epidemic has been documented over the past two decades throughout

\section{STRENGTHS AND LIMITATIONS OF THIS STUDY}

$\Rightarrow$ The study provides an international view of the importance of adequately assessing smoking prevalence by validating the accuracy of self-reported smoking questionnaires.

$\Rightarrow$ The misclassification bias of smokers needs to be examined in rural populations.

$\Rightarrow$ Urine cotinine and self-reported smoking status were investigated concurrently at multiple crosssectional time points.

$\Rightarrow$ The study results may have limited generalisability as it was conducted among agricultural workers in Guatemala.

Latin America, Sri Lanka and India. ${ }^{1}$ CKDu is not associated with established CKD risk factors such as diabetes or hypertension and the aetiology remains unknown. ${ }^{1}$ Several CKDu risk factors have been proposed, including heat stress, dehydration, environmental exposures, infectious agents, medications, as well as a multifactorial aetiology. ${ }^{1-6}$

Smoking, as opposed to other CKD risk factors, has received less attention in epidemiological studies in populations at risk for CKDu despite the evidence of its role with CKD. Scientific literature provides both mechanistic and epidemiological evidence linking smoking to kidney disease and it is an established and independent CKD risk factor. ${ }^{7-9}$ While few studies have found an association between self-reported smoking and $\mathrm{CKDu},{ }^{10-13}$ there may be multiple reasons for the lack of association findings. First, tobacco use misclassification is common and there is considerable heterogeneity between misclassification rates, ${ }^{14}$ especially among light or non-daily smokers. ${ }^{15}$ This misclassification 
potentially leads to the underestimation of the harmful effects of smoking. Here, we present data on the validity of self-reported smoking status against urinary cotinine levels in a sample of workers at risk for CKDu in Guatemala. Cotinine, the main nicotine metabolite, accumulates in the body as a result of tobacco exposure and can be easily detected in urine, blood and saliva. Urine cotinine is commonly used as an objective measure to distinguish tobacco users and nonusers. ${ }^{16}$ Second, research on how smoking is assessed in rural populations in low-income countries where CKDu is endemic is lacking. Smoking patterns in CKDu endemic areas may be different from those in urban populations and in highincome countries, where smoking is intermittent. ${ }^{17-20}$ Third, while smoking may not be the main cause of CKDu, it may serve as an effect modifier or accelerate disease progression, as it is a well-established CKD risk factor. ${ }^{7}$

Therefore, we provide evidence that smoking should be objectively measured using biomarkers, such as cotinine, in CKDu epidemiological studies and should not be assessed in the same manner as in high-income countries, where smoking practices are likely different.

\section{METHODS}

\section{Study Design}

The data for this analysis were derived from two studies among male agricultural workers ( $\geq 18$ years) employed by a sugarcane agribusiness in Guatemala. One study was conducted during the 2016-2017 harvest among 81 field workers and the other study during the 2017-2018 harvest among 202 field workers. The harvest season lasts 6 months from November through May.

The 2016-2017 participants were randomly recruited within a population of workers in December 2016. The 20172018 participants were a similar but separate population of workers and were randomly recruited within four work groups of workers in November 2017. During the 2016-2017 study, we collected survey data and spot urine samples in February 2017. During the 2017-2018 study, we collected survey data and spot urine samples at three time points: November 2017 (4 groups), January 2018 (2 randomly selected groups among the 4 groups) and April 2018 (4 groups). This gave us a total of 283 matched urine and participant surveys with self-reported smoking status.

For the 2016-2017 study, participants were asked at the end of their 8-10hour work shift in February: 'how many cigarettes have you smoked since you woke up this morning?' by a Spanish-speaking interviewer (not employed by the agribusiness). At enrollment in November for the 2017-2018 study, participants were asked 'do you smoke cigarettes?'. Participants responded that they were either current smokers, former smokers or had never smoked. Former smokers were also asked 'how old were you when you quit smoking?'. At the other two time points during the 2017-2018 study, January and April, the participants were asked at the end of their 8-10 hour work shift: 'how many cigarettes have you smoked since you woke up this morning?'.
Urine samples were collected in morning except at the November time point, where 95 samples $(47 \%)$ were collected in the afternoon. A common practice with urine analytes is to correct for urine creatinine to adjust for dilutional effects. However, studies documenting the usefulness of correcting cotinine levels for urine creatinine are limited and may not be necessary. ${ }^{21}$ We did not correct for urine creatinine based on the limited correction information and after establishing that our afternoon urine creatinine levels were dilute, and dehydration was not a concern.

\section{Laboratory analysis}

Urine cotinine levels were determined using the Calbiotech Cotinine ELISA CO096D (Calbiotech, E1 Cajon, California, USA) and the limit of detection was $5 \mathrm{ng} / \mathrm{mL}$. A cotinine-verified non-smoker was defined as having urinary cotinine $\leq 50 \mathrm{ng} / \mathrm{mL}$. This threshold value was used as the cut-off according to the Society for Research on Nicotine and Tobacco and is consistent with being a current smoker. ${ }^{22}$

\section{Statistical analysis}

We compared self-reported smoking status and urine cotinine categories $(\leq 50 \mathrm{ng} / \mathrm{mL}$ vs $>50 \mathrm{ng} / \mathrm{mL})$ in November 2017. Participants were excluded $(n=50)$ if they had missing survey data or urine samples. Agreement between self-report and cotinine levels was assessed using the McNemar's test. We calculated sensitivity (cotinine: $>50 \mathrm{ng} / \mathrm{mL}$ and reported being a current smoker) and specificity (cotinine: $\leq 50 \mathrm{ng} /$ $\mathrm{mL}$ and reported being a non-smoker) using urinary measurements as the gold standard. Similarly, at the three other time points (February 2017, January 2018 and April 2018), cotinine categories were compared with self-reported cigarette use on the study day. All data analyses were performed in SAS V.9.4.

\section{Patient and public involvement}

These two studies included a collaborative process that engaged workers and worker representatives in the development, implementation and dissemination plans of the research to enhance its relevance and impact. They were not involved in the data analysis or interpretation of this research.

\section{RESULTS}

November 2017 urinary cotinine level distributions for the 202 participants are presented in table 1 and figure 1. Among 150 participants (74\%) who reported had never smoked, $39(26 \%)$ had cotinine levels $>50 \mathrm{ng} / \mathrm{mL}$ and among 28 participants (14\%) who reported being a former smoker, $10(36 \%)$ had cotinine levels $>50 \mathrm{ng} / \mathrm{mL}$. Based on responses to the question, 'how old were you when you quit smoking?', none of the former smokers had high cotinine levels due to having just quit. To assess the accuracy of 
Table 1 Urine cotinine levels by self-reported smoking status in November 2017, N=202

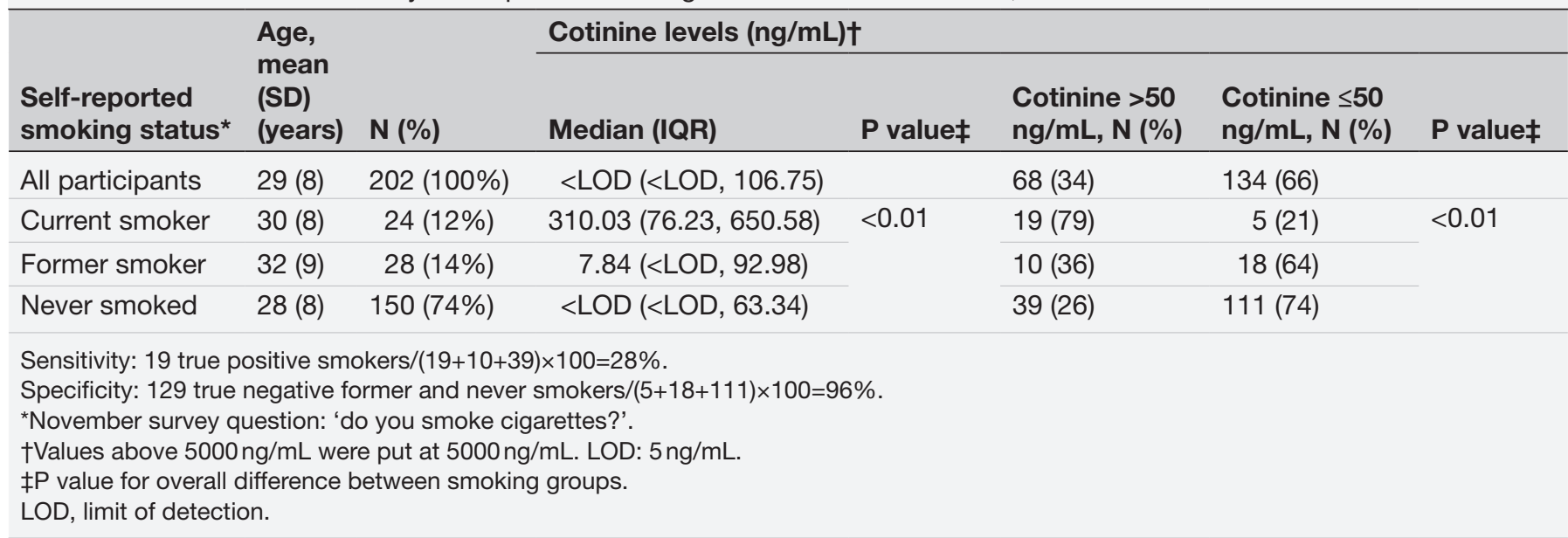

self-reported data, sensitivity and specificity were calculated. Self-reported smoking status had a sensitivity of $28 \%$ and specificity of $96 \%$, indicating that $72 \%$ of the workers identified as smokers by the urine cotinine test reported being a former or never smoker and $4 \%$ of workers identified as non-smokers by the urine cotinine test reported themselves as a current smoker. Smoking status and cotinine levels were not associated (McNemar's test, $\mathrm{p}<0.05$ ).

For both the studies, the percent of participants who reported no cigarettes on the day of the study but had cotinine levels $>50 \mathrm{ng} / \mathrm{mL}$ was $21 \%$ in February 2017 , 26\% in January 2018 and 25\% in April 2018 (table 2).

Therefore, using these two study populations of agricultural field workers, we found that approximately $25 \%$ of participants who would be considered non-smokers based on self-reported smoking status had an objective measurement of recent tobacco exposure with urine cotinine concentration of $>50 \mathrm{ng} / \mathrm{mL}$.

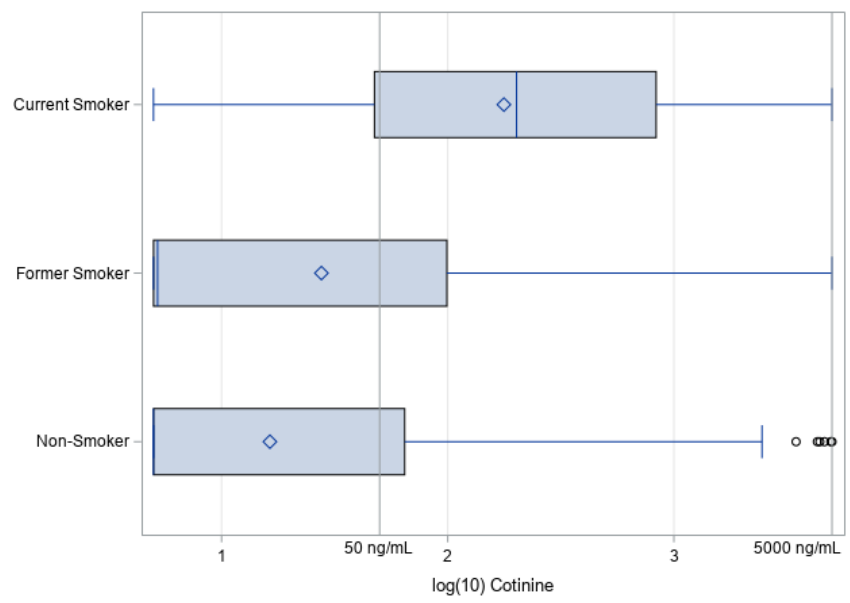

Figure 1 Box plots of $\log _{10}$ urine cotinine levels by selfreported smoking status in November 2017.

\section{DISCUSSION}

In this study, we evaluated self-reported smoking status of agricultural workers using an established biomarker of smoke exposure, urinary cotinine. We observed that selfreported smoking status likely underestimates smoking prevalence in this population. The prevalence of smoking was $34 \%$ based on cotinine and $12 \%$ based on self-reported data, indicating that self-reporting led to an underestimation of smoking by $64 \%$. The self-reported smoking prevalence in our study was much lower than the last national survey on smoking in Guatemala (2003), where $24 \%$ of males self-reported as current smokers (definition: smoked $\geq 1$ cigarettes in the past 30 days) ${ }^{2324}$

Data on smoking exposure in CKDu studies have mostly been dependent on self-reports and yielded conflicting findings on the association with kidney dysfunction. Several studies have found that current or ever smokers are at a higher risk of kidney dysfunction. Among 330 sugarcane workers in Guatemala, we found that self-reported current smokers (vs never or former smokers) were at a significantly

Table 2 Urinary cotinine levels ( $\leq 50 \mathrm{ng} / \mathrm{mL}$ vs $>50 \mathrm{ng} / \mathrm{mL}$ ) by reported cigarette use on study day, $\mathrm{n}(\%)$

\begin{tabular}{|c|c|c|c|}
\hline \multicolumn{4}{|l|}{ 2016-2017 study* } \\
\hline February 2017, n=81 & Overall & $\leq 50 \mathrm{ng} / \mathrm{mL}$ & $>50 \mathrm{ng} / \mathrm{mL}$ \\
\hline Smoked cigarette(s) & $4(5 \%)$ & $2(50 \%)$ & $2(50 \%)$ \\
\hline Did not smoke & 77 (95\%) & $61(79 \%)$ & $16(21 \%)$ \\
\hline \multicolumn{4}{|l|}{ 2017-2018 study ${ }^{*}$} \\
\hline January 2018, n=92 & Overall & $\leq 50 \mathrm{ng} / \mathrm{mL}$ & $>50 \mathrm{ng} / \mathrm{mL}$ \\
\hline Smoked cigarette(s) & $1(1 \%)$ & $0(0 \%)$ & $1(100 \%)$ \\
\hline Did not smoke & $91(99 \%)$ & 67 (74\%) & $24(26 \%)$ \\
\hline April 2018, n=167 & Overall & $\leq 50 \mathrm{ng} / \mathrm{mL}$ & $>50 \mathrm{ng} / \mathrm{mL}$ \\
\hline Smoked cigarette(s) & $10(6 \%)$ & $2(20 \%)$ & $8(80 \%)$ \\
\hline Did not smoke & $157(94 \%)$ & $117(75 \%)$ & $40(25 \%)$ \\
\hline
\end{tabular}

*Survey question: 'how many cigarettes have you smoked since you woke up this morning?'. 
greater risk for a decline in kidney function over a harvest season. ${ }^{10}$ Two studies conducted in Sri Lankan agricultural workers found that smoking (current or ever) was a risk factor for CKDu. ${ }^{12}{ }^{13}$ In addition, patients with biopsyproven tubulointerstitial kidney disease in Sri Lanka were more likely to have ever used tobacco. ${ }^{11}$ Three studies in Nicaragua have found smoking to be a risk factor in univariate analyses and smoking was either controlled for in the multivariable analysis or was no longer significant. ${ }^{25-27}$ Other studies found no relationships between smoking and kidney dysfunction and/or very low smoking prevalence ${ }^{28-32}$ There was a wide prevalence range of self-reported smoking among these community and worker studies. While smoking assessments varied substantially, the most common question to assess smoking was whether participants were current or ever smokers.

Tobacco use misclassification could introduce bias and be one reason for these conflicting results; true smoking rates are likely underestimated as our current findings yield. This misclassification bias could potentially be leading to the underestimation of the harmful effects of smoking on populations at risk for CKDu. In addition, rates of smoking misclassification have been found to be higher in diseased groups and in case-control studies, suggesting that the presence of disease may affect smoking status response. ${ }^{14}$

Smoking status misclassification is likely due to several reasons. One is the social desirability bias, where smokers misclassify themselves as non-smokers due to cultural pressure to quit smoking. In addition, these data were collected at a worksite with a smoke-free workplace policy in place. Although workers were assured that their survey responses would be kept confidential, they may have felt pressure to deny smoking. Another reason is the difference in smoking patterns between high-income countries and low-income and middle-income countries (LMICs), where CKDu is endemic. One study found differing patterns of current smoking and type of cigarette smoked (light vs regular) across Brazil, China, Mexico and Poland. ${ }^{33}$ In Guatemala, like other Latin American countries and Latinos in the USA, light smoking and non-daily smoking are highly prevalent. ${ }^{19}{ }^{20}$ Furthermore, single-cigarette sales are very common in Guatemala City and neighbouring towns. ${ }^{17}$ In another study conducted between 2001 and 2004, it was found that non-daily smoking was common among men in several Central American countries (42\% in El Salvador, $23 \%$ in Guatemala and $19 \%$ in Honduras). ${ }^{19}$ These studies provide insight on smoking patterns in CKDu endemic countries in Central America; it is very possible that light or non-daily smokers do not consider themselves 'smokers' and may under-report their cigarette use in epidemiological surveys. ${ }^{34}$ Capturing different smoking patterns among populations at risk for $\mathrm{CKDu}$ is an essential step toward accurately documenting tobacco smoke exposure in epidemiological research. While survey-based, self-reported smoking is commonly used to assess smoking status due to its low cost, and ease of use, investigators should be cautious when interpreting smoking prevalence given our findings that self-reported smoking status can be inaccurate. Regular validity tests (ie, biomarkers of smoke exposure) should be performed to compensate for the limitations of selfreported smoking surveys. In addition, questions should aim to capture patterns of both daily and non-daily smokers. A 2014 Global Adult Tobacco Survey stressed the importance of three basic questions to measure tobacco smoking prevalence, which includes questions on current use (both daily and less than daily responses available), past use for non-daily smokers and past use for current non-smokers. These type of improved survey questions on smoking exposure should be evaluated with objective measure, such as cotinine in epidemiological studies of CKDu.

Our study findings have some limitations. It may be difficult to generalise the results as they are from a rural agricultural worker population. While cotinine is commonly used to discern smokers from non-smokers, there may be an overlap between cotinine levels of non-smokers exposed to high levels of secondhand smoke and light/non-daily smokers. Further research should focus on assessing the optimal cut-off point for validating smoking status among agricultural populations in LMICs. While the discrepancy between urinary cotinine levels and cigarette use on the study day is consistent between February 2017, January 2018 and April 2018, we must interpret these findings with caution. A cotinine level of $>50 \mathrm{ng} / \mathrm{mL}$ might reflect a current smoker who did not smoke any cigarettes on the study day and could reflect smoking the previous day. In addition, 24-hour urine sample collection would be a more reliable parameter for the assessment of diuresis, although less feasible in epidemiological studies.

In this report, we are not taking the position that smoking is the sole cause of CKDu. However, smoking is a wellestablished and important modifiable risk factor for several diseases, including CKD. ${ }^{7}$ We have a disease of 'unknown' origin and tobacco use has not been fully explored, in part due to self-report misclassification. Thus, understanding unique aspects of smoking is needed among populations at risk for $\mathrm{CKDu}$ and future studies need more objective measurements of smoking as a risk factor for the development of CKDu.

\section{Author affiliations}

${ }^{1}$ Department of Environmental and Occupational Health, Colorado School of Public Health, University of Colorado, Aurora, Colorado, USA

${ }^{2}$ Center for Health, Work and Environment, Colorado School of Public Health, University of Colorado, Aurora, Colorado, USA

${ }^{3}$ Integra Cancer Institute, Guatemala City, Guatemala

${ }^{4}$ Unit for Cardiovascular Surgery, Unidad de Cirugía Cardiovascular de Guatemala,

UNICAR, Guatemala City, Guatemala

${ }^{5}$ Pantaleon, Guatemala City, Guatemala

${ }^{6}$ Division of Pulmonary Sciences and Critical Care Medicine, Department of Medicine, School of Medicine, and Department of Epidemiology, Colorado School of Public Health, University of Colorado, Aurora, CO, USA

Acknowledgements We wish to thank all our collaborators, including Alex Cruz, Daniel Pilloni and all the workers who have made this work possible.

Contributors Conceptualisation: JB-D and JB. Data curation: LK. Formal analysis: WF and JB-D. Funding acquisition: LSN. Methodology: JB-D, SB, LK and LSN. Guarantor: JB-D. Project administration: LK. Visualisation: JB-D, JB and LSN. Writing —original draft: JB-D and SB. Writing—review and editing: JB, LK, SB, WF, CA and LSN. 
Funding This study was supported by Centers for Disease Control and Prevention (U19 OH011227) and National Institutes of Health (R21 ES028826), and in part by Pantaleon and by the Chancellor, University of Colorado, CU Anschutz Campus. Funders had no role in data analysis, interpretation of data, writing the manuscript or the decision to submit the findings for publication.

Competing interests University of Colorado and Pantaleon are separate, independent organisations. University of Colorado employed appropriate research methods in keeping with academic freedom, based conclusions on critical analysis of the evidence and reported findings fully and objectively. The terms of this arrangement have been reviewed and approved by the University of Colorado in accordance with its conflict of interest policies.

\section{Patient consent for publication Not applicable.}

Ethics approval All participants provided a written consent prior to enrollment. Both protocols were approved by the institutional review board of the University of Colorado (COMIRB, \#16-1824 and \#17-1328) and in Guatemala by the Comité de Ética, Facultad de Medicina, Universidad Francisco Marroquin-Hospital Universitario Esperanza (2016-2017 study) and the Comité de Ética Independiente ZUGUEME (2017-2018 study).

Provenance and peer review Not commissioned; externally peer reviewed.

Data availability statement Data are available upon reasonable request. Data Sharing Agreement: The data that support the findings of this study are available from the corresponding author, JBD, upon reasonable request.

Open access This is an open access article distributed in accordance with the Creative Commons Attribution Non Commercial (CC BY-NC 4.0) license, which permits others to distribute, remix, adapt, build upon this work non-commercially, and license their derivative works on different terms, provided the original work is properly cited, appropriate credit is given, any changes made indicated, and the use is non-commercial. See: http://creativecommons.org/licenses/by-nc/4.0/.

\section{ORCID iD}

Jaime Butler-Dawson http://orcid.org/0000-0002-1325-6246

\section{REFERENCES}

1 Johnson RJ, Wesseling C, Newman LS. Chronic kidney disease of unknown cause in agricultural communities. $N$ Engl J Med 2019;380:1843-52

2 Glaser J, Lemery J, Rajagopalan B, et al. Climate change and the emergent epidemic of CKD from heat stress in rural communities: the case for heat stress nephropathy. Clin J Am Soc Nephrol 2016;11:1472-83.

3 Bodin T, García-Trabanino R, Weiss I, et al. Intervention to reduce heat stress and improve efficiency among sugarcane workers in El Salvador: phase 1. Occup Environ Med 2016;73:409-16.

4 Wesseling C, Crowe J, Hogstedt C, et al. The epidemic of chronic kidney disease of unknown etiology in Mesoamerica: a call for interdisciplinary research and action. Am J Public Health 2013;103:1927-30.

5 Crowe J, Wesseling C, Solano BR, et al. Heat exposure in sugarcane harvesters in Costa Rica. Am J Ind Med 2013;56:1157-64.

6 García-Trabanino R, Jarquín E, Wesseling C, et al. Heat stress, dehydration, and kidney function in sugarcane cutters in El Salvador-A cross-shift study of workers at risk of Mesoamerican nephropathy. Environ Res 2015;142:746-55.

7 Orth SR. Smoking and the kidney. J Am Soc Nephrol 2002;13:1663-72.

8 Xia J, Wang L, Ma Z, et al. Cigarette smoking and chronic kidney disease in the general population: a systematic review and metaanalysis of prospective cohort studies. Nephrol Dial Transplant 2017;32:475-87.

9 Choi HS, Han K-D, Oh TR, et al. Smoking and risk of incident endstage kidney disease in general population: a nationwide populationbased cohort study from Korea. Sci Rep 2019;9:19511.

10 Butler-Dawson J, Krisher L, Asensio C, et al. Risk factors for declines in kidney function in sugarcane workers in Guatemala. J Occup Environ Med 2018:60:548-58.

11 Anand S, Montez-Rath ME, Adasooriya D, et al. Prospective BiopsyBased study of CKD of unknown etiology in Sri Lanka. Clin J Am Soc Nephrol 2019;14:224-32.
12 Ruwanpathirana T, Senanayake S, Gunawardana N, et al. Prevalence and risk factors for impaired kidney function in the district of Anuradhapura, Sri Lanka: a cross-sectional populationrepresentative survey in those at risk of chronic kidney disease of unknown aetiology. BMC Public Health 2019;19:763.

13 Wanigasuriya KP, Peiris-John RJ, Wickremasinghe R. Chronic kidney disease of unknown aetiology in Sri Lanka: is cadmium a likely cause? BMC Nephrol 2011;12:32

14 Hamling JS, Coombs KJ, Lee PN. Misclassification of smoking habits: an updated review of the literature. World $J$ Metaanal 2019;7:31-50.

15 US Department of Health and Human Services. Smoking cessation. A report of the surgeon General. Atlanta, GA: U.S. Department of Health and Human Services, Centers for Disease Control and Prevention, National Center for Chronic Disease Prevention and Health Promotion, Office on Smoking and Health, 2020.

16 Balhara YPS, Jain R. A receiver operated curve-based evaluation of change in sensitivity and specificity of cotinine urinalysis for detecting active tobacco use. J Cancer Res Ther 2013;9:84-9.

17 de Ojeda A, Barnoya J, Thrasher JF. Availability and costs of single cigarettes in Guatemala. Nicotine Tob Res 2013;15:83-7.

18 Levy D, Zavala-Arciniega L, Reynales-Shigematsu LM, et al. Measuring smoking prevalence in a middle income nation: an examination of the 100 cigarettes lifetime screen. Glob Epidemiol 2019;1:100016

19 Tong VT, Turcios-Ruiz RM, Dietz PM, et al. Patterns and predictors of current cigarette smoking in women and men of reproductive ageEcuador, El Salvador, Guatemala, and Honduras. Rev Panam Salud Publica 2011;30:240-7.

20 Barnoya J, Glantz S. Knowledge and use of tobacco among Guatemalan physicians. Cancer Causes Control 2002;13:879-81.

21 Jatlow P, McKee S, O'Malley SS. Correction of urine cotinine concentrations for creatinine excretion: is it useful? Clin Chem 2003:49:1932-4.

22 SRNT Subcommittee on Biochemical Verification. Biochemical verification of tobacco use and cessation. Nicotine Tob Res 2002:4:149-59.

23 World Bank Group. Guatemala : Overview of Tobacco Use, Tobacco Control Legislation, and Taxation. Washington D.C: World Bank Group, 2019.

24 World Health Organization. Guatemala metropolitan area steps 2015 fact sheet, 2015.

25 Lebov JF, Valladares E, Peña R, et al. A population-based study of prevalence and risk factors of chronic kidney disease in León, Nicaragua. Can J Kidney Health Dis 2015;2:41.

26 Wesseling C, Aragón A, González M, et al. Heat stress, hydration and uric acid: a cross-sectional study in workers of three occupations in a hotspot of Mesoamerican nephropathy in Nicaragua. BMJ Open 2016;6:e011034.

27 Kupferman J, Ramírez-Rubio O, Amador JJ, et al. Acute kidney injury in sugarcane workers at risk for Mesoamerican nephropathy. Am J Kidney Dis 2018;72:475-82.

28 Gonzalez-Quiroz M, Smpokou E-T, Silverwood RJ, et al. Decline in kidney function among apparently healthy young adults at risk of Mesoamerican nephropathy. J Am Soc Nephrol 2018;29:2200-12.

29 Gallo-Ruiz L, Sennett CM, Sánchez-Delgado M, et al. Prevalence and risk factors for CKD among Brickmaking workers in La PAZ Centro, Nicaragua. Am J Kidney Dis 2019;74:239-47.

30 Glaser J, Hansson E, Weiss I, et al. Preventing kidney injury among sugarcane workers: promising evidence from enhanced workplace interventions. Occup Environ Med 2020;77:527-34.

31 Butler-Dawson J, Krisher L, Yoder H, et al. Evaluation of heat stress and cumulative incidence of acute kidney injury in sugarcane workers in Guatemala. Int Arch Occup Environ Health 2019;92:977-90.

32 Dally M, Butler-Dawson J, Cruz A, et al. Longitudinal trends in renal function among first time sugarcane harvesters in Guatemala. PLoS One 2020;15:e0229413.

33 Blackford AL, Yang G, Hernandez-Avila M, et al. Cotinine concentration in smokers from different countries: relationship with amount smoked and cigarette type. Cancer Epidemiol Biomarkers Prev 2006;15:1799-804.

34 Schane RE, Glantz SA, Ling PM. Nondaily and social smoking: an increasingly prevalent pattern. Arch Intern Med 2009;169:1742-4.

35 Wray JM, Gass JC, Miller El, et al. A comparative evaluation of selfreport and biological measures of cigarette use in nondaily smokers. Psychol Assess 2016;28:1043-50. 